\title{
Experimental rabbit model of meningitis produced by Haemophilus influenzae serotype $\mathrm{c}$
}

\author{
P. SULC, B. HENGSTLER, G. KRINKET, T. O'REILLY and O. ZAK*
}

Departments of Pharma Research and TToxicological Pathology (Product Safety), CIBA-GEIGY Limited, Basel, Switzerland, $\mathrm{CH}-4002$

\begin{abstract}
Summary. The virulence of Haemophilus influenzae type $\mathrm{c}$ when inoculated intracisternally (i.c.) into rabbits was evaluated. Rabbits are relatively resistant to infection with $H$. influenzae type $b$, such that inocula of the order of $10^{6-9} \mathrm{cfu}$ are required to produce meningitis in this model. In contrast, fatal meningitis was produced in this study when $10^{3} \mathrm{cfu}$ of a type-c strain were injected i.c. into rabbits. Numbers of bacteria in cerebrospinal fluid (CSF) of control (untreated) animals generally increased to $10^{7} \mathrm{cfu} / \mathrm{ml}$. Increases in white blood cells, protein and lactate in the CSF were similar to those which had been observed during meningitis due to Streptococcus pneumoniae in rabbits. The infection was amenable to therapy with ampicillin $50 \mathrm{mg} / \mathrm{kg}$ given intravenously $12 \mathrm{~h}$ after infection. Numbers of bacteria in CSF were reduced to $2 \cdot 2 \times 10^{3} \mathrm{cfu} / \mathrm{ml}\left(\right.$ SEM $0.2 \times 10^{3}$ ) at $8 \mathrm{~h}$ after treatment with a single dose of ampicillin. Two doses of ampicillin, given 12 and $20 \mathrm{~h}$ after infection, significantly increased the mean survival time. In contrast to previous experimental studies with rabbits, the penetration of ampicillin into the CSF was high-46 (SEM 10) \% of the blood level. Since considerable replication of $H$. influenzae type c occurred within the CSF in this model, the nature of the meningeal damage produced was likely to be similar to that which takes place in man. Hence, $H$. influenzae type $\mathrm{c}$ meningitis in rabbits may provide a useful model in which therapeutic and other experimental studies of $H$. influenzae meningitis can be performed.
\end{abstract}

\section{Introduction}

Although rabbits are susceptible to meningeal infection with Streptococcus pneumoniae when the organism is administered intracisternally (i.c.) $)^{1}$ they are relatively resistant to experimental meningeal infection with Haemophilus influenzae. ${ }^{2}$ Consequently, high inocula $\left(10^{6-9} \mathrm{cfu}\right)$ of $H$. influenzae type $\mathrm{b}$ have been used to produce a rabbit meningitis model for therapeutic studies with antimicrobial agents ${ }^{3-9}$ and adjunct anti-inflammatory agents, ${ }^{10}$ and for evaluation of the importance of tumour necrosis factor in the pathogenesis of meningitis. ${ }^{11}$ After the introduction of large numbers of organisms into the cerebrospinal fluid (CSF), apparently in order to overcome the naturally occurring antibodies ${ }^{12}$ which are thought to render the animal resistant to infection, ${ }^{2}$ little or no increase in numbers of bacteria occurs. Therefore, such infections may not closely mimic natural infections with $H$. influenzae in which considerable increases in numbers of bacteria in the CSF occur.

$H$. influenzae serotype $c$ causes meningitis only occasionally in man. ${ }^{13,14}$ Although the clinical presentation appears similar to cases caused by type-b

Received 19 Sep. 1990; revised version accepted 4 July 1991.

* Correspondence should be sent to Dr O. Zak. strains, $\boldsymbol{H}$. influenzae type-c strains are considered to be much less virulent than type-b strains. ${ }^{15}$ The chemical composition and antigenicity of the type-c capsule differs from that of the type-b polysaccharide. ${ }^{16}$ Furthermore, type-c strains differ from type-b strains in outer membrane protein ${ }^{17}$ and lipooligosaccharide ${ }^{18}$ composition, which may also result in a different antigenic profile between type-c and type-b strains. Therefore $H$. influenzae type c may elude the naturally occurring antibodies in rabbits that react with type-b strains. The purpose of the present study was to examine the virulence of a type-c strain in a rabbit model of meningitis, and to determine whether the infection produced could be modified by antimicrobial therapy.

\section{Materials and methods}

\section{$H$. influenzae type-c}

The organism used in all experiments was $H$. influenzae P27, a clinical isolate confirmed to be of capsule type $c$ by slide agglutination with type-specific antisera (Difco); it was stored at $-70^{\circ} \mathrm{C}$ in Brain Heart Infusion Broth (BHI; Difco) supplemented with IsoVitalex (Becton-Dickinson) $1 \% \mathrm{v} / \mathrm{v}$ and fetal calf 
serum $10 \%$. Inocula for the production of animal infections were prepared by diluting overnight cultures into freshly supplemented BHI broth. Organisms were allowed to grow to mid-exponential phase $\left(c .10^{8} \mathrm{cfu} /\right.$ $\mathrm{ml}$, estimated by turbidimetry) before being harvested by centrifugation at $2000 \mathrm{~g}$ for $10 \mathrm{~min}$ and resuspended in pyrogen-free saline (PFS) to c. $5 \times 10^{3} \mathrm{cfu} / \mathrm{ml}$. Numbers of viable bacteria were determined by further dilutions of these suspensions in BHI broth which were then plated on to "chocolate" agar plates.

\section{Model of meningitis}

The experimental protocols were approved by the ethical committee of Vetinäramt für Kanton Basel Stadt. Chinchilla rabbits, $2-3 \mathrm{~kg}$ in weight, (specific pathogen free, obtained from Thomae, Biberach and der Riss, Germany) were fitted with prostheses as described previously. ${ }^{1}$ Before infection, rabbits were given ethyl carbamate (urethane) $1.75 \mathrm{~g} / \mathrm{kg}$ by subcutaneous (s.c.) injection, followed by pentobarbital $10 \mathrm{mg} / \mathrm{kg}$ intravenously (i.v.) to induce long-term anaesthesia. The animals were then positioned in stereotactic frames and 3.5-in spinal needles $(25 \mathrm{~g})$ sited in the cisterna magna were used to withdraw $0.3 \mathrm{ml}$ of CSF and to introduce $0.2 \mathrm{ml}$ of bacterial suspension. Deeply anaesthetised animals remained in the frames up to $24 \mathrm{~h}$ after infection to facilitate repeated CSF sampling and were then removed to cages. Subsequent CSF sampling was performed after repeat anaesthesia with pentobarbital. The rate of removal of CSF did not exceed the rate of CSF formation $\left(c .0 .4 \mathrm{ml} / \mathrm{h} .{ }^{19}\right)$ Blood samples were taken into syringes containing heparin $(0.15 \mathrm{U} / \mathrm{ml}$ of blood, final concentration) by ear or saphenous vein puncture.

\section{Determination of indices of meningitis}

Numbers of white (WBC) and red (RBC) blood cells in CSF and blood were determined with a Sysmex cell counter (model CC-170M, TDA Corp., Kobe, Japan). Counts of viable bacteria were estimated by dilution of CSF in BHI broth and plating on to "chocolate" agar plates. Concentrations of protein, lactate and glucose in CSF were determined as described previously. ${ }^{20}$ Histological examination of paraffin-embedded sections of brains which had been fixed by immersion in formalin $4 \%$ was performed after staining with haematoxylin and eosin ( $\mathrm{H}$ and $\mathrm{E})$.

\section{Antimicrobial therapy of $H$. influenzae type $c$ meningitis}

At 12 and $20 \mathrm{~h}$ after infection, eight animals were given ampicillin $50 \mathrm{mg} / \mathrm{kg}$ as an i.v. bolus; controls $(n=5)$ received an equivalent volume of PFS. Ampicillin present in CSF and blood samples obtained for the determination of bacterial numbers was inactivated by the addition of penicillin-amido- $\beta$-lactamhydrolase (EC 3.5.2.6, from Bacillus cereus; Genzyme
Biochemicals Ltd, Maidstone, Kent) $1 \mathrm{U} / \mathrm{ml}$ to the BHI broth used for diluting samples. Concentrations of ampicillin in samples taken for pharmacokinetic studies were determined by bioassay; indicator organisms were either Micrococcus luteus ATCC 9341 (CSF) or B. subtilus ATCC 6633 (plasma). The MIC of ampicillin for $H$. influenzae P27 was determined by a macro broth dilution technique with an inoculum of $10^{6} \mathrm{cfu} / \mathrm{ml}$. The MBC $(99.99 \%$ kill) was determined by subculture of $10-\mu l$ volumes on to "chocolate" agar plates.

\section{Statistical methods}

Where indicated, values given are geometric means (cfu and WBC counts); other mean values are arithmetic means. Variation is depicted by the SEM represented by numbers in parentheses. The paired Student's $t$ test was used to compare data obtained before and after ampicillin treatment. The Wilcoxon rank sum test was used to compare mean survival times.

\section{Results}

\section{Characteristics of experimental $H$. influenzae type c meningitis}

Preliminary experiments demonstrated that i.c. inocula of $3 \cdot 2 \times 10^{8}, 6 \cdot 3 \times 10^{7}$, or $3.2 \times 10^{6}$ cfu resulted in no increase in bacterial counts in CSF and that inoculation with $5 \times 10^{5} \mathrm{cfu}$ resulted in only a limited extent of growth to $c .10^{6} \mathrm{cfu} / \mathrm{ml}$. Figs. $1-4$ present the data obtained from a representative experiment in which the inoculum was $c .10^{3} \mathrm{cfu}$. Inoculation of rabbits with $1.6 \times 10^{3} \mathrm{cfu}$ was followed by bacterial replication such that numbers increased to around $10^{7} \mathrm{cfu} / \mathrm{ml}$. Numbers of bacteria in the CSF doubled approximately every $250 \mathrm{~min}$ between $1 \mathrm{~h}$ and $12 \mathrm{~h}$ after infection, with a very rapid increase during the late stages of untreated infections leading to death of the animals (fig. 1). All untreated animals died; the mean survival time was 34 (SEM 3) h after infection

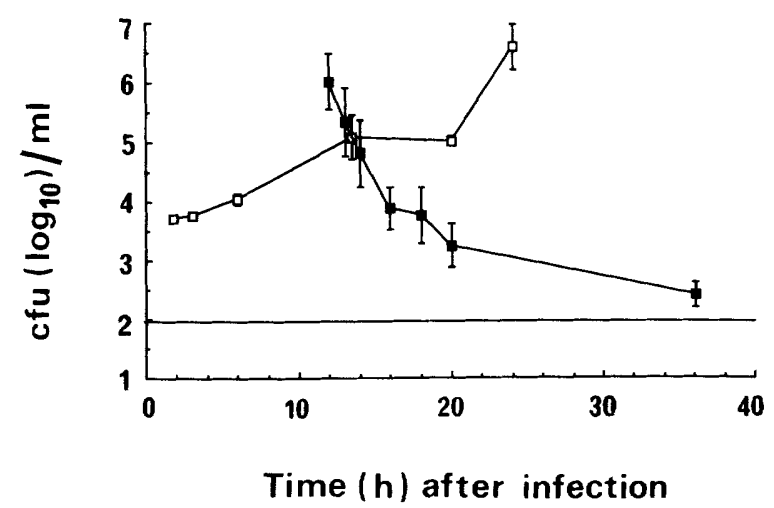

Fig. 1. Growth of $H$. influenzae type c following i.c. injection of $1.6 \times 10^{3}$ cfu of $H$. influenzae strain P27 into rabbits that were given either saline $(n=5, \square)$ or ampicillin $(50 \mathrm{mg} / \mathrm{kg}$ i.v. $) 12$ and $20 \mathrm{~h}$ after infection $(n=8, \square)$. Symbols represent mean values and vertical bars represent $S E M$. 


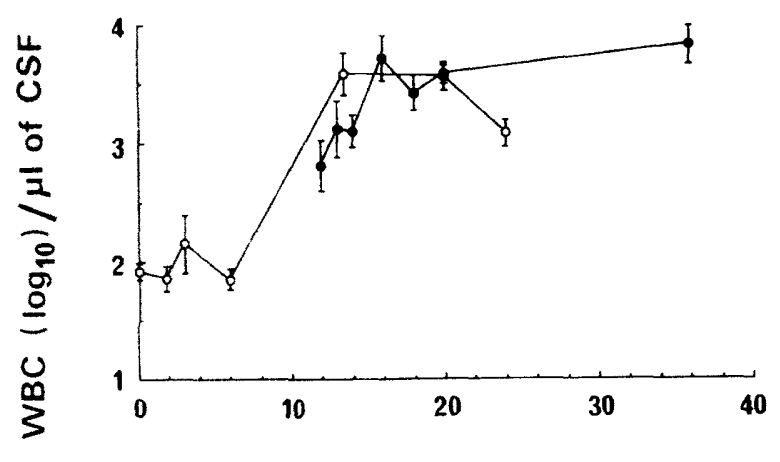

Time $(h)$ after infection

Fig. 2. Pleocytosis after i.c. injection of $1.6 \times 10^{3} \mathrm{cfu}$ of $H$. influenzae type $c$ into rabbits that were given either saline $(n=5, O)$ or ampicillin $(50 \mathrm{mg} / \mathrm{kg}$ i.v. $) 12$ and $20 \mathrm{~h}$ after infection $(\mathrm{n}=8,0)$. Symbols represent mean values and vertical bars represent SEM.

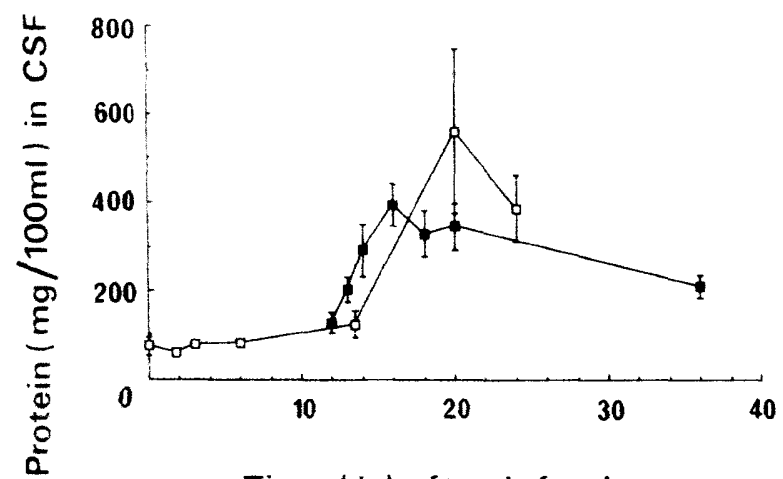

Time $(\mathrm{h})$ after infection

Fig. 3. CSF protein content changes during the course of experimental $H$. influenzae type c meningitis in rabbits given $1.6 \times$ $10^{3} \mathrm{cfu}$ of strain P27 and either saline $(n=5, \square)$ or ampicillin $(50 \mathrm{mg} / \mathrm{kg}$ i.v.) 12 and $20 \mathrm{~h}$ after infection $(\mathrm{n}=8, \square)$. Symbols represent mean values and vertical bars represent SEM.

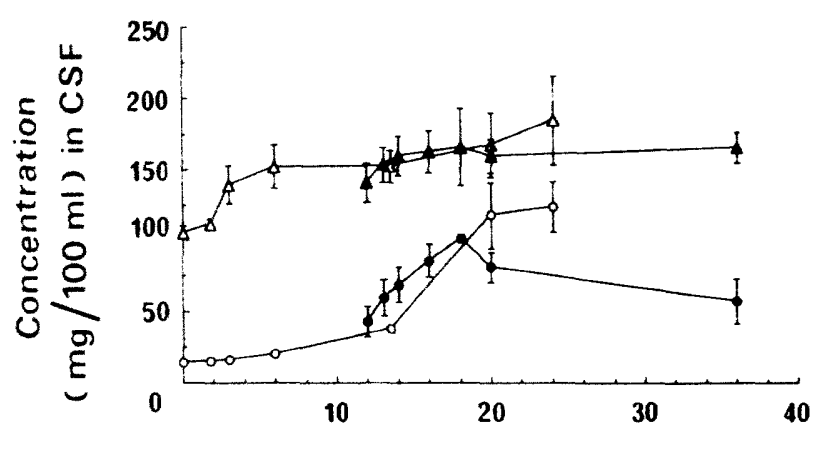

Time ( $h$ ) after infection

Fig. 4. CSF lactate and glucose content changes during the course of experimental $H$. influenzae type $c$ meningitis in rabbits given $1.6 \times 10^{3}$ cfu of strain P27. The lactate $(0, \boldsymbol{\theta})$ and glucose $(\triangle, \boldsymbol{\Delta})$ content of CSF from animals given saline $(O, \triangle i n=5$ ) or ampicillin $(50 \mathrm{mg} / \mathrm{kg}$ i.v. $)(\boldsymbol{O}, \Delta ; \mathrm{n}=8)$ treatment 12 and $20 \mathrm{~h}$ after infection were determined enzymatically. Symbols represent mean values and vertical bars represent SEM.

(range $27-42 \mathrm{~h})$. Bacteraemia $\left(>1 \times 10^{2} \mathrm{cfu} / \mathrm{ml}\right)$ was not detected until $10-12 \mathrm{~h}$ after infection. $H$. influenzae was always cultured from blood taken post mortem, but numbers varied from $10^{6}$ to $10^{9} \mathrm{cfu} / \mathrm{ml}$. For reasons that are unknown, the bacterial density in CSF of animals that were sampled at $12 \mathrm{~h}$ after infection was higher than in those that had been repeatedly sampled.

Meningitis was accompanied by a marked increase in WBC in the CSF, of which more than $80 \%$ of the total WBC were granulocytes (fig. 2). An increase in WBC content preceded any rise in protein concentration (fig. 3). Concentrations of lactate rose slowly until $12 \mathrm{~h}$ after infection, after which there was a rapid rise (fig. 4). CSF glucose levels rose rapidly at first before stabilising at a concentration which was more than $150 \%$ of initial levels (fig. 4).

Histological examination of brains demonstrated acute purulent meningitis and meningo-encephalitis characterised by the presence of exudate containing numerous polymorphonuclear cells (rabbit heterophilic cells) and by the formation of thrombi, especially at the base of the brain.

\section{Ampicillin therapy of $H$. influenzae type $c$ meningitis}

The MIC and MBC of ampicillin for $H$. influenzae P27 was $0.25 \mathrm{mg} / \mathrm{L}$. Ampicillin administration $(50 \mathrm{mg} /$ $\mathrm{kg}$ i.v.) to eight animals 12 and $20 \mathrm{~h}$ after infection resulted in a decrease in bacterial numbers in the CSF (fig. 1), as well as a reduction in numbers of bacteria in the blood to below the limit of detectability $(<$ $20 \mathrm{cfu} / \mathrm{ml}$ ). Before the second dose of ampicillin, bacterial counts in CSF declined, on average, by $2 \cdot 1($ SEM $0 \cdot 2) \times 10^{3} \mathrm{cfu} / \mathrm{ml}$ in six animals and counts declined below the limit of detectability $(<1 \cdot 2 \times$ $10^{2} \mathrm{cfu} / \mathrm{ml}$ ) in the other two rabbits. Ampicillin therapy resulted in significant $(p<0.001)$ decreases in measured bacterial counts in $\mathrm{CSF}$, compared to numbers of organisms present immediately before administration of the drug. Therapy was associated with an increase in mean survival time to 52 (SEM 3) $h$ (range $32-72 \mathrm{~h}$ ) significantly $(\mathrm{p}<0.05)$ longer than in untreated animals. Numbers of organisms in CSF and blood were below detectable limits in three of eight treated animals post mortem. $H$. influenzae type $c$ was cultured from the CSF (range $10^{3}-10^{6} \mathrm{cfu} / \mathrm{ml}$ ) and from the blood (range $10^{2}-10^{4} \mathrm{cfu} / \mathrm{ml}$ ) of the other five treated rabbits.

Ampicillin therapy was associated with WBC counts in CSF similar to those observed in untreated animals (fig. 2). However, at $36 \mathrm{~h}$ after infection, or post mortem, WBC populations in ampicillin-treated animals consisted of granulocytes $60 \%$ and lymphocytes and monocytes $40 \%$. Although the protein concentration in the CSF increased after therapy, this change was similar to that seen in untreated animals (fig. 3). Ampicillin therapy resulted in a decrease in CSF lactate concentrations at $20 \mathrm{~h}$ after infection compared with controls, but this difference was not statistically significant. There was no difference in CSF glucose concentrations between treated and untreated animals (fig. 4).

Studies of the pharmacokinetics of ampicillin, estimated in five animals, demonstrated that the 
concentration of ampicillin in plasma was 31 (SEM 10) $\mathrm{mg} / \mathrm{L} 0.5 \mathrm{~h}$ after i.v. injection. Ampicillin was eliminated from the blood with $t_{1 / 2}=0 \cdot 11$ (SEM $0.03) h$ and $t_{1 / 2 \beta}=1.6$ (SEM 0.3) $h$. The area under the curve (AUC) was estimated to be 112 (SEM 19) $\mathrm{mg} \times \mathrm{h} / \mathrm{L}$. The peak CSF concentration of ampicillin was $3.8($ SEM 1.1$) \mathrm{mg} / \mathrm{L}$ (approximately $15 \times \mathrm{MBC})$ $1 \mathrm{~h}$ after injection, with a CSF elimination $\mathrm{t}_{1 / 2}$ of 1.5 (SEM 0.1 ) h. The AUC was 8.4 (SEM 3) $\mathrm{mg} \times \mathrm{h} / \mathrm{L}$. The peak CSF/plasma ratio of 46 (SEM10) \% was found $1 \mathrm{~h}$ after injection. Accordingly, the ampicillin levels in CSF were above the MBC for c. $6.4 \mathrm{~h}$ after injection.

\section{Discussion}

In studies of $H$. influenzae type $\mathrm{b}$ meningitis in the rabbit model of Darcey and Sande, ${ }^{1}$ very high inocula $\left(10^{6-9} \mathrm{cfu}\right)$ have been required to establish infection. Following the introduction of large numbers of organisms, the pattern of bacterial growth (or persistence) within the CSF was variable. Some workers have reported no increase, or even a decrease, in bacterial numbers; ${ }^{3-5,7}$ others have detected a moderate, apparently immediate increase. ${ }^{9}$ A marked increase in bacterial numbers has also been reported after a period of 14-16 h during which little or no bacterial growth occurred. ${ }^{6,8}$ In contrast, the present study has demonstrated that increases in bacterial numbers continued for at least $24 \mathrm{~h}$ after introduction of $10^{3} \mathrm{cfu}$ of $H$. influenzae serotype c into rabbit CSF. The doubling time for bacteria in the CSF was slow $(250 \mathrm{~min})$ relative to the growth rate observed in vitro in supplemented BHI broth $(40 \mathrm{~min})$. This net growth rate in vivo is considerably slower than the net growth rate in vivo of $H$. influenzae type $\mathrm{b}$ in rat blood $(82 \mathrm{~min}){ }^{21}$ However, the reasons for the relatively slow growth rate and for the virulence of this strain in this model are not clear.

The increases in WBC count and concentration of lactate in the CSF which followed $H$. influenzae type c infection were similar to those which have been observed when $H$. influenzae type b has been used in this model. ${ }^{9}$ The concentration of protein in the CSF was higher than that reported after i.c. injection of amounts of lipo-oligosaccharide ${ }^{22}$ or outer membrane vesicles ${ }^{23}$ equivalent to $c .10^{7} \mathrm{cfu} H$. influenzae type b, but similar to that observed when rabbits were infected with $S$. pneumoniae. ${ }^{24}$ These differences may be explained by the continuous stimulation of an inflammatory response during prolonged infection in contrast with the transient inflammatory response which results from injection of various cell components ${ }^{24,25}$ or proinflammatory cytokines. ${ }^{26}$ The increase in CSF glucose concentration observed was similar to that found when infant rats were infected with $H$. influenzae type b. ${ }^{27}$ While the reasons for this difference between man and experimental animals is unclear, it may be accounted for partly by the use of anaesthetics in the present study.

The meningitis model described was affected by therapy with moderate doses of ampicillin $(50 \mathrm{mg} / \mathrm{kg})$ which resulted in an increased mean survival time of infected rabbits. The decline in bacterial density $-2 \cdot 1$ (SEM $0 \cdot 2) \times 10^{3} \mathrm{cfu} / \mathrm{ml}$ by $8 \mathrm{~h}$ after ampicillin administration-was similar to that observed in studies of $H$. influenzae type b infections $\left(7.9 \times 10^{3} \mathrm{cfu} / \mathrm{ml}^{3}\right.$; $3.9 \times 10^{4} \mathrm{cfu} / \mathrm{ml}^{4} ; 7.9 \times 10^{4} \mathrm{cfu} / \mathrm{ml}^{7}$; all rates determined by comparing pre-treatment bacterial counts with those observed at $8 \mathrm{~h}$ after ampicillin treatment). Generally, bacteriological cure of meningitis in man can be obtained with appropriate antibiotic therapy, and ampicillin is still widely used to treat $H$. influenzae meningitis in areas where susceptibility is still likely to be observed in the clinic. ${ }^{28}$ In the case of this model, successful therapy of an infection with a strain sensitive to ampicillin indicated that the animal was not so severely compromised due to anaesthetic, infection route, an excessively virulent strain, or an inoculum dose so high that therapy with ampicillin was unsuccessful; this suggests that the use of this model for evaluation of novel antimicrobial therapy would indeed be valid.

During the initial stages of $H$. influenzae type c meningitis, the population of WBC present in the CSF was composed of $80 \%$ granulocytes. Interestingly, although the total number of WBC in the CSF changed little, the composition of WBC in the CSF of ampicillin-treated animals changed to only $60 \%$ granulocytes, the remainder being lymphocytes. This may indicate a change in the nature of the inflammatory response between that occurring at the onset of infection and that occurring during the course of treatment. This shift in the qualitative composition of WBC in the CSF has also been observed during sterile meningitis induced by the i.c. injection of cytokines. ${ }^{26}$

Although changes in CSF protein were similar in untreated and treated animals, CSF lactate concentrations tended to decrease after administration of ampicillin. This decrease in lactate has also been observed during ampicillin therapy of $S$. pneumoniae ${ }^{29}$ and ceftriaxone therapy of $H$. influenzae type b meningitis. ${ }^{10}$

Ampicillin pharmacokinetics were characterised by a CSF ampicillin concentration which exceeded that deemed necessary to achieve bacteriological cure of meningitis $(>10 \times \mathrm{MBC})^{30}$ with the CSF $\mathrm{t}_{1 / 2}$ being similar to the $t_{1 / 2 \beta}$ of serum-1.5 (SEM 0.1) and 1.6 (SEM 0.3) h, respectively. However, the penetration of ampicillin into CSF-46 (SEM 10) \% of blood levels - was much higher than that reported in studies which have employed either bolus injection $(3 \%$ penetration; $;^{3} 15 \%$ penetration ${ }^{5}$ ) or continuous infusion $\left(19 \%\right.$ penetration $;{ }^{4} 13 \%$ penetration $\left.{ }^{7}\right)$ for treatment of experimental $\boldsymbol{H}$. influenzae type b meningitis. Although the penetration of ampicillin into the CSF of patients with inflamed meninges is considered to be quite low at $8-13 \%,{ }^{31}$ a recent study demonstrated 
that the CSF concentration of ampicillin was $39 \%$ of the blood level when meningitic children were given $400 \mathrm{mg} / \mathrm{kg} /$ day, ${ }^{32}$ results similar to those found here. The prolonged and progressive infection due to $H$. influenzae type $\mathrm{c}$ in the present model may induce meningeal damage such that the penetration of ampicillin is similar to that which occurs in a clinical case. This is likely to be in contrast to the situation which develops when meningeal inflammation results from a sudden infection with a large inoculum of organisms. However, in the present study, we cannot exclude the possibility that the urethane anaesthetic contributed to the high penetration of ampicillin into the CSF.

In conclusion, a reliable model of meningitis in rabbits was established by the i.c. inoculation of $\boldsymbol{H}$. influenzae type c. In contrast to infections in rabbits produced by type-b strains, in the present model, inoculation of only $10^{3} \mathrm{cfu}$ of $\boldsymbol{H}$. influenzae type c i.c.

\section{References}

1. Dacey RG, Sande MA. Effect of probenecid on cerebrospinal fluid concentrations of penicillin and cephalosporin derivatives. Antimicrob Agents Chemother 1974; 6: 437-441.

2. Scheld WM. Experimental animal models of bacterial meningitis. In: Zak O, Sande MA (eds) Experimental models in antimicrobial chemotherapy, vol 1. London, Academic Press. 1986: 139-186.

3. Bodine JA, Strausbaugh LJ, Sande MA. Ampicillin and an ester in experimental Hemophilus influenzae meningitis. Clin Pharmacol Ther 1976; 20 : 727-732.

4. Strausbaugh LJ, Mandaleris CD, Sande MA. Cefamandole and ampicillin therapy in experimental Haemophilus influenzae meningitis. $J$ Infect Dis $1977 ; 135$ : 210-216.

5. Perfect JR, Lang SDR, Durack DT. Comparison of cotrimoxazole, ampicillin, and chloramphenicol in treatment of experimental Haemophilus influenzae type b meningitis. Antimicrob Agents Chemother 1980; 17: 43-48.

6. McCracken GH, Nelson JD, Grimm L. Pharmacokinetics and bacteriological efficacy of cefoperazone, cefuroxime, ceftriaxone, and moxalactam in experimental Streptococcus pneumoniae and Haemophilus influenzae meningitis. Antimicrob Agents Chemother 1982; 21 : 262-267.

7. Scheld WM, Brodeur JP, Sande MA, Alliegro GM. Comparison of cefoperazone with penicillin, ampicillin, gentamicin, and chloramphenicol in the therapy of experimental meningitis. Antimicrob Agents Chemother 1982; 22: 652656.

8. Sakata Y, McCracken GH, Thomas ML, Olsen KD. Pharmacokinetics and therapeutic efficacy of imipenem, ceftazidime, and ceftriaxone in experimental meningitis due to an ampicillin- and chloramphenicol-resistant strain of Haemophilus influenzae type b. Antimicrob Agents Chemother $1984 ; 25: 29-32$.

9. Syrogiannopoulos GA, Al-Sabbagh A, Olsen KD, McCracken GH. Pharmacokinetics and bacteriological efficacy of ticarcillin-clavulanic acid (Timentin) in experimental Escherichia coli $\mathrm{K}-1$ and Haemophilus influenzae type b meningitis. Antimicrob Agents Chemother 1987; 31 : 1296 1300.

10. Syrogiannopoulos GA, Olsen KD, Reisch JS, McCracken GH. Dexamethasone in the treatment of experimental Haemophilus influenzae type b meningitis. J Infect Dis 1987; 155: 213-219.

11. Mustafa MM, Ramilo O, Olsen KD et al. Tumor necrosis factor in mediating experimental Haemophilus influenzae type b meningitis. J Clin Invest 1989; 84: 1253-1259.

12. Schneerson R, Robbins JB. Age-related susceptibility to Haemophilus infiuenzae type $\mathrm{b}$ disease in rabbits. Infect Immun $1971 ;$ 4: 397-401.

13. Berg U, Bohlin B-H, Malmborg A-S. Neonatal meningitis led to a fatal infection accompanied by marked increases in bacterial numbers in the CSF. With the exception of the concentration of glucose, cytochemical changes in the CSF were similar to those seen in patients. The penetration of ampicillin was higher than that observed previously when meningitis has been triggered by injection of large inocula of $H$. influenzae type-b strains. These observations suggest that progressive infection, associated with increasing CSF bacterial density after injection of low numbers of $H$. influenzae type c, provides a rabbit model of $H$. influenzae meningitis which more closely mimics the clinical situation. Hence, the use of $\boldsymbol{H}$. influenzae type c to establish meningitis in rabbits may be a better experimental model than that which results from infection with $H$. influenzae type b.

We thank Doris Schläpfer and Fabienne Schaeffer for technical assistance.

caused by Haemophilus influenzae type c. Scand J Infect Dis $1981 ; 13: 155-157$.

14. Neihart RE, Hodges GR, Papasian CJ, Rengachary SS Nosocomial Hemophilus influenzae type c meningitis in an adult. Diagn Microbiol Infect Dis 1987; 6: 69-71.

15. Zwahlen A, Winkelstein JA, Moxon ER. Surface determinants of Haemophilus influenzae pathogenicity: Comparative virulence of capsular transformants in normal and complement-depleted rats. $J$ Infect Dis 1983 ; 148 : 385-394.

16. Moxon ER. Hemophilus influenzae. In: Mandell GL, Douglas RG, Bennett JE (eds) Principles and practice of infectious diseases, 2nd edn. New York, John Wiley and Sons Inc. 1985: 1274-1279.

17. Loeb MR, Smith DH. Outer membrane protein composition in disease isolates of Haemophilus influenzae: Pathogenic and epidemiological implications. Infect Immun 1980; 30: 709 717.

18. Zamze SE, Moxon ER. Composition of the lipopolysaccharide from different capsular serotype strains of Haemophilus influenzae. J Gen Microbiol 1987; 133: 1443-1451.

19. Spector R, Lorenzo AV. Inhibition of penicillin transport from the cerebrospinal fluid after intracisternal inoculation of bacteria. J Clin Invest 1974; 54 : 316-325.

20. Tuomanen $E$, Tomasz A, Hengstler $B$, Zak $O$. The relative role of bacterial cell wall and capsule in the induction of inflammation in pneumococcal meningitis. $J$ Infect $D$ is $1985 ; 151$ : $535-540$.

21. Rubin LG. Comparison of in vivo and in vitro multiplication rates of Haemophilus influenzae type b. Infect Immun 1986; 52: $911-913$.

22. Syrogiannopoulos GA, Hansen EJ, Erwin AL et al. Haemophilus influenzae type $\mathrm{b}$ lipooligosaccharide induces meningeal inflammation. J Infect Dis 1988; 157: 237-244.

23. Mustafa MM, Ramilo O, Syrogiannopoulos GA, Olsen KD, McCracken GH, Hansen EJ. Induction of meningeal inflammation by outer membrane vesicles of Haemophilus influenzae type b. J Infect Dis 1989; 159: 917-922.

24. Kadurugamuwa JL, Hengstler B, Zak O. Cerebrospinal fluid protein profile in experimental pneumococcal meningitis and its alteration by ampicillin and anti-inflammatory agents. J Infect Dis 1989; 159: 26-34.

25. Kadurugamuwa JL, Hengstler B, Bray MA, Zak O. Inhibition of complement-factor-5a-induced inflammatory reactions by prostaglandin $\mathrm{E}_{2}$ in experimental meningitis. $J$ Infect Dis 1989 ; 160: 715-719.

26. Saukkonen K, Sande S, Cioffe C et al. The role of cytokines in the generation of inflammation and tissue damage in experimental gram-positive meningitis. J Exp Med 1990; 171 : $439-448$

27. Moxon RE, Smith AL, Averill DR. Brain carbohydrate metabolism during experimental Haemophilus infuenzae meningitis. Pediatr Res 1979; 13 : 52-59. 
28. Kayser FH, Morenzoni G, Santanam P. The 2nd European collaborative study on the frequency of antimicrobial resistance in Haemophilus influenzae. Eur J Clin Microbiol Infect Dis 1990; 9: 810-817.

29. Täuber MG, Khayam-Bashi H, Sande MA. Effects of ampicillin and corticosteroids on brain water content, cerebrospinal fluid pressure, and cerebrospinal fluid lactate levels in experimental pneumococcus meningitis. J Infect Dis 1985; 151 : $528-534$.

30. Decazes JM, Ernst JD, Sande MA. Correlation of in vitro timekill curves and kinetics of bacterial killing in cerebrospinal fluid during ceftriaxone therapy of experimental Escherichia coli meningitis. Antimicrob Agents Chemother 1983; 24: 463-467.

31. Norris S, Nightingale $\mathrm{CH}$, Mandell GL. Tables of antimicrobial pharmacology. In: Mandell GL, Douglas RG, Bennett JE (eds) Principles and practice of infectious diseases, 3rd edn. New York, Churchill Livingstone. 1990: 434-460.

32. Foulds G, McBride TJ, Knirsch AK, Rodriguez WJ, Khan WN. Penetration of sulbactam and ampicillin into cerebrospinal fluid of infants and young children with meningitis. Antimicrob Agents Chemother 1987; 31 : 1703-1705. 